Sama D. Salman

\title{
Pragmatic Equivalence in Subtitling Arabic Culture-Specific Idiomatic Expressions into English
}

\author{
Sama D. Salman \\ Misr International University
}

\begin{abstract}
This study aims to investigate the possibility of achieving pragmatic equivalence in the translation of culture-specific Idiomatic Expressions (IE) used in a number of Egyptian Arabic movies into English. It is hypothesized that pragmatic equivalence is achievable, pending the choice of the right translation strategy that fits the context. Translation samples of parts of seven Egyptian movies, attempted by undergraduate students enrolled in a subtitling course in a private Egyptian university, are analyzed according to Baker's pragmatic equivalence concept (1992). The analysis focuses on the strategies adopted by the students to deal with culture-specific idiomatic expressions, and how far the selected strategy can affect the Source Language (SL) intended message and the Target Language (TL) audience. The results reveal that pragmatic equivalence is achievable, and that there is no such thing as "the best" translation strategy to deal with IEs, though paraphrase is the most common strategy adopted by the students. The decision regarding the translation strategy is usually made on an ad hoc basis, depending on the context of situation and the competence of the translator. Therefore, there is a need to introduce classroom activities that train students to consider the pragmatic dimension of the SL message when translating IEs. The study concludes that would-be translators should perfect their translation skills by acquiring pragmatic competence to be able to function in the culture of the language they are translating into as native speakers do.
\end{abstract}

Keywords: pragmatic equivalence, Arabic-English subtitling, idiomatic expressions 


\section{Introduction}

Equivalence is a central concept in translation. A number of approaches has been suggested to the study of equivalence in relation to translation. Among the earliest scholars who studied this issue is Roman Jacobson (1959) who believes that there is no full equivalence between language units (as cited in Munday, 2001, p. 36). Few years later, Nida (1964) focused on how the cultural context can change the meaning of words. He was among the first theorists to attract the attention to pragmatic equivalence when he drew the distinction between formal equivalence (the form and content of the message) and dynamic equivalence (the effect of the message on the audience) (as cited in Munday, 2001, pp. 41-42). And while Nida favors dynamic translation as it more faithfully renders the intention of the author, Newmark, on the other hand, considers it, most of the time, unachievable due to cultural gaps (1988, p. 48). Koller (1979) goes beyond this dichotomy to divide equivalence into five types: denotative (when the words in the two languages refer to the same thing in the real world); connotative (when the words in the two languages trigger the same associations); text normative (when the words in the two languages are used in the same context); pragmatic (when the words in the two languages produce the same effect on the audience) and formal equivalence (when the words in the two languages have the same form), (as cited in Kenny, 2001, p.77). In 1992, Mona Baker, in her book In Other Words: A Coursebook on Translation, distinguished between equivalence at word level (the meaning of single words); equivalence above word level (combination of words); grammatical equivalence (grammatical categories); textual equivalence (word order and cohesion); and pragmatic equivalence (how texts are used in different cultural contexts). She argues that equivalence 


\section{Sama D. Salman}

is relative and can be affected by many linguistic and cultural factors ( $p$. 23).

This study aims to find out whether or not pragmatic equivalence is achievable in the translation of culture-specific Idiomatic Expressions (IEs) through analyzing samples of students' translation of Egyptian Arabic movies into English. The strategies that students use to deal with such expressions are identified and analyzed according to Baker's pragmatic equivalence concept (1992).

The study hypothesizes that pragmatic equivalence is achievable when translating culture-specific IEs if the right translation strategy is adopted. This decision is believed to be dependent on the context of situation, and the translator's semantic as well as pragmatic competence.

The study attempts to find answers to the following questions:

1) To what extent is pragmatic equivalence achievable when translating Arabic culture-specific IEs into English?

2) What are the translation strategies that can be adopted to deal with culture-specific IEs, and which strategy is the most adequate?

3) How far can linguistic competence alone guarantee faithful rendition of movie scripts?

\section{Literature Review}

\section{Baker's Pragmatic Equivalence (1992)}

The fact that translation involves the transfer of two cultures has motivated scholars to come up with various approaches to help translators deal with the cultural difficulties they face. One of these approaches is Baker's pragmatic equivalence.

In her book In Other Words: A Coursebook on Translation (1992), Baker follows a bottom-top approach to discuss five types of equivalence 
that begins with the word level then moves to texts used in cultural contexts (p.6). The first type is the equivalence at the word level, which is related to the problems the translator faces when a single word has no equivalent in the other language. The second type deals with the cases when words combine with one another to form stretches of language, such as collocations, idioms and fixed expressions, and she calls it the equivalence above word level. The third type of equivalence she discusses is the grammatical equivalence which is related to such notions as time, number, gender, person and so on, and how languages express them differently. Textual equivalence is concerned with firstly, how words could be arranged in sentences to control information flow, and secondly with the relations that link parts of a text (i.e. cohesion). The last chapter of Baker's book is devoted to the fifth type of equivalence, which is the concern of the present study, namely, pragmatic equivalence.

Baker defines Pragmatics as "the study of language in use", and she introduces what she terms "pragmatic equivalence" to refer to the influence of the text on the TL audience. For her, this concept explains how people use languages in communicative situations, and how they can be understood (p.217).

Baker (1992) believes that translation is challenging for two main reasons: first, because people of different cultures have different experiences and views towards the world events (p. 219); and second, because the rules of interaction among people are not universal and a great deal of communication is achieved by what is implied rather than by what is stated (p.223). She maintains that translators, when dealing with culture-specific expressions, should make a balance between making the target language comprehensible to the TL audience, on the one hand, and 


\section{Sama D. Salman}

providing them with new experiences and views of the world, on the other hand (p. 254).

When it comes to cross-culture communication, Baker (1992) underlines two main concepts: coherence and implicature. Coherence denotesef the "network of conceptual relations which underlie the surface text" (p.218). It entails that people's ability to understand sentences depends on their expectations and experiences. And since people of different cultures may view the world differently, what makes sense in one society may not be so in another one. In other words, sentences are not coherent by themselves, but their coherence depends on the audiences' ability to relate them to their prior knowledge of the world. This means, Baker goes on to say, that translators should take into consideration the knowledge and expectations of their audience when they translate culture-specific elements (pp. 221-222).

The other pragmatic notion that Baker discusses is implicature, which is, according to Grice (1975), refers to what is implied but not literally stated (as cited in Baker, 1992, p. 223). Grice's Cooperative Principle suggests that communication among people is connected and has a goal that participants cooperate to achieve. The principle is based on four basic maxims of conversation that are considered guidelines to achieve effective co-operative use of language. The Cooperative Principle does not claim that all speakers adopt this communicative behavior all the time, but rather that hearers usually assume that those maxims are being adhered to. And when any of the maxims is violated by speakers, hearers use their contextual background to infer the intended implicature. Baker sees this principle significant to translators because mistranslation of words can negatively affect the ability of the TL audience to understand what is implied. Therefore, she maintains that translators' role is to meet 
the audiences' assumptions and 'bridge the gap between the textual world and the world of the target reader" by resorting to translation strategies (pp. 229-232). Furthermore, she believes that translators have to judge what kind of knowledge the TL audience needs in order to make the right inference since failure to relate a text to their knowledge can lead the TL audience to draw the wrong inference from the text. Therefore, the texts that do not meet the expectations of the TL audience should be "adjusted" by the translator (p. 250).

\section{Subtitling and Cultural Translatability}

Subtitling is a form of audiovisual translation where written texts are "superimposed on visual footage that convey a target language version of the source speech" (Perez-Conzalez, 2014, pp. 15-16). Similarly, subtitling is defined by Perego (2003) as, the "translation of the spoken source language text of an audiovisual product ... into a written text, which is superimposed onto the image of the original product" ( $p$. 63). Subtitling, as all other types of translation, is influenced by cultural factors, and it influences the TL audience.

The close interrelation between language and culture in subtitling causes problems in translating culture-specific elementsco from spoken dialogue into written subtitles. This is because translators of movies do not deal with individual words, but whole texts that are embedded in the cultural settings of the movie. The cultural problems involved in subtitling have attracted the attention of scholars; however, the number of studies dealing with this issue is still limited (Pedersen, 2005, p.2).

Goodenough (1964) defines culture as "the form of things that people have in mind, their model of perceiving and dealing with their circumstances" (as cited in Armellino, 2014). According to Newmark 


\section{Sama D. Salman}

(1988), five areas constitute cultures, namely, ecology; material culture (e.g. food and clothes); social culture; customs and ideas; and gestures and habits (p. 95). And since subtitling involves the translation of all these components, it requires highly attentive translators (Pedersen, 2011, p.41). Hatim and Mason note that translation of cultural references requires translators who are both "bi-lingual" and "bi-cultural" to mediate between the two cultures (1990, p. 223).

Furthermore, Ramière (2006) believes that translation of movies raises many cross - cultural issues since it tries to bring cultures into contact with one another. The most important of these issues is the effect that translation strategies create on audience's perceptions of the SL culture. Sajna (2013) points out that the difficulty in translating culturespecific elements in movies is that if they were replaced with other expressions that are familiar to the TL audience, the translator may be accused of cheating. However, if everything in the original is left intact, the TL audience may fail to understand a certain scene. Therefore, Durdureanu (2011) highlights that translators need to adopt some strategies to deal with those cultural aspects that have no equivalent in the other language, among which are formal equivalence, borrowing and selfexplanatory translation (p.51). The decision to use one strategy rather than another is not made randomly but is based on a number of contextual factors. Georgakopoulou (2009) stresses that the decision of the translation strategy in subtitling culture-specific elements depends on a number of factors such as the relevance of such element to the plot, the implied information, and the target audience's knowledge and culture (p.29). Similarly, Ramière (2006) points out that when it comes to screen translation, contextual elements play a very significant role since movies usually "imply strong contextual embeddedness". She defines these 
contextual elements as those that include nonverbal signs and camera shots, genre of the movie, target audience, and distribution context, among others. She argues that translators' choice of the strategy affects how the TL audience perceive the film. This implies that translators of movies should be competent enough to be able to make the right decision. Skuggevik (2009) underlines five levels of competence that screen translators should possess: technical competence; linguistic competence; cultural competence in both languages involved; ability to understand the psychological or emotional dimension of words; and the competence to take all these levels into account to decide the best translation strategy (p.198).

This entails that translators of movies are expected to have a semantic and pragmatic competence, the former to convey the sense of the text, while the latter to be able to grasp the intention of using a particular text on a certain occasion by a given speaker (House, 1997, p. 31). Adequate translation, therefore, is the one that accounts for the speaker's intentions so as to produce the intended effect; otherwise there will be pragmatic failure (i.e. the inability to grasp what is meant by what is said). This usually results when participants fail to understand each other's' intentions due to their different linguistic or cultural background. Thomas (1983) considers pragmatic failure one of the main reasons for cross-cultural communication breakdown. He distinguishes between a speaker's linguistic competence, which consists of the rules of phonology, syntax, and semantics; and pragmatic competence that refers to the ability to effectively use language to achieve certain purposes (as cited in Cutting, 2002, p. 159). Hence, in order for translators to be pragmatically competent, they must have the ability to act linguistically in such a way as to meet the expectations of the TL audiences. 


\section{Sama D. Salman}

\section{Translation of Idiomatic Expressions}

As has been mentioned, the most challenging problems that face translators of movies are those related to cultural differences between the two languages involved. This is because movies usually include culturespecific elements and expressions that may or may not exist in the target language. Salumahaleh and Mirzayi (2014) define cultural-specific expressions as those that have no equivalents in the TL cultural system (p.223). Suleiman (2010) notes that the difficulty in dealing with such expressions arises either because of unfamiliarity with the cultural term, or inability to find an equivalent in the other language ( $\mathrm{Al}$ Abwaini, 2013, p.34). Armellino (2014) warns that the problem of translating culturebound terms in films is that some of them are clear, whereas others are not. Some elements, such as colloquial tones, are implied and should be dealt with carefully. Baker (1992) points out that some IEs are untranslatable because they are related to culture-specific contexts (p.68). On the contrary, Ghazala (2002) holds the view that "everything in language is translatable in a way or another including cultural expressions" (p. 170).

Regarding the translation of Arabic IEs into English, Ayoub (1994) mentions that translation of IEs is one of the problematic areas in the translation between these two languages, and that the context is very crucial for determining their intended meaning and for selecting the most adequate way to translate them (as cited in Al Abwaini, 2013, p.22). In the same vein, Mahmoud (2002) notes that Arab culture is reflected in many language-specific IEs that create a challenge to translators, as the transfer of such expressions to English may result in comprehension problems. 
Baker (1992) defines IEs as "frozen patterns of language which allow little or no variation in form and ... often carry meanings which cannot be deduced from their individual components" (p. 63). They could be proverbs, collocations, metaphors, or idioms that are related to a specific culture. She notes that IEs are used frequently because they can easily bring into the mind of the audience all the aspects of experience that are related to the context in which they are used (p.64).

According to Baker (1992, pp. 68-71), the translation of IEs involves four difficulties: a) the SL IE may have no equivalent in the TL since users of language differ in the way they express a given meaning; $b$ ) the SL IE has a counterpart in the TL but is used in a different context or carries different connotations; a matter which makes it pragmatically not transferable; c) the IE is used in the SL in a literal as well as an idiomatic sense (e.g. in humor and play on words), and d) the SL and TL may differ in terms of the stylistic preferences (Arabic users, unlike English ones, tend to avoid using IEs in written texts).

That is why Baker (1992) suggests four strategies to deal with such expression: 1) Using a TL IE with similar meaning and form (i.e. has equivalent lexical items and conveys the same meaning); 2) Using an IE with a similar meaning but with a different form; 3) Paraphrasing though it may not be very accurate; and when all these strategies do not work, the only option would be 4) deleting the IE altogether (pp. 71-77). Baker maintains that the context where a given IE is used should be the basis upon which translators choose one strategy over another. She agrees with Fernando and Flavell (1981) that translators should be careful when dealing with IEs in order not to force a given IE into the TL text (as cited in Baker, 1992, p. 72). The effectiveness of each of these strategies 


\section{Sama D. Salman}

suggested by Baker in rendering Arabic IEs into English is the main concern of this paper.

\section{Methodology}

This study is a descriptive analysis of the English translation of parts of some Egyptian Arabic movies attempted by groups of undergraduate students. Clips from seven Arabic movies were translated by the students into English as part of the requirements of a subtitling course. The movies are viewed by the researcher to identify and select the most challenging culture-bound IEs. The basis of selection is not the quantity, but rather the difficulty involved when rendering the Arabic IEs into English. The attempted translation of these IEs are compared with the original scripts in order to define the strategies that are used by the students. These strategies are categorized according to the classification suggested by Baker (1992). The analysis focuses on how far the selected strategy is effective in achieving pragmatic equivalence to a given SL IE in terms of expressing its intended meaning and creating a similar effect on the TL audience.

\section{Subjects}

The subjects in this study are all native speakers of Arabic. They are 21 students enrolled in a subtitling course in the Department of English, Faculty of Al-Alsun (Languages \& Translation) in an Egyptian private university. The students worked in groups of three; each group was responsible for translating and proofreading a 30-minute-long part of an Arabic movie of their own choice. Each student was required to completely translate 10 minutes individually and the three students were 
responsible for proofreading, editing and presenting the whole 30 minutes.

\section{Data}

The data comprises students' English translation of parts of seven Egyptian Arabic movies: دعاء الكروان (The Nightingale's Prayer), باب الحديد (Cairo Station), إثناعة حب(A Rumor of Love), الر هينة (The Hostage), تيمور (Taymor and Shafika), عسل اسود (Molasses) and صغيرة على الحبة. Too Young for Love). The translations of the movies are reviewed against the original scripts, and examples of the most challenging, culture-specific IEs used are selected to be analyzed. The culture-bound IEs mentioned in these movies are detected and compared with their English subtitles to identify the strategies that the students used to translate them. Then, the frequency of the used strategies is investigated to find out which one is the most commonly used, and which one helps achieve pragmatic equivalence.

\section{Data Analysis}

Example (1)

هنادي قابلت ربها

\section{Hanadi met her God}

The first example to be discussed here is from the Egyptian movie دعاء (The Nightingale's Prayer). In this example, Amna, the main character in the movie, is saying that her sister هنادي passed away using the Arabic euphemism قابلت ربها . The students translated this Arabic IE literally into "met her God" which may have a religious connotation in the TL culture but it, definitely, does not convey the intention of the speaker. The students resorted to none of the strategies underlined by Baker (1992), but they translated the IE literally, resulting in pragmatic 


\section{Sama D. Salman}

failure as the translation fails to deliver the intention of the speaker and leads the audience to the wrong inference.

Example (2)

ايدك عالحلاوة

I want my candy

Another IE from the same movie is إيدك عالحلاوة, an Egyptian expression used when asking for some kind of commission or reward in return for a favor or a service. Again the students translated the expression literally. The translation is irrelevant to the context, and it delivers a wrong message because the speaker in the scene is not asking for candies but for money. Just like the case with example (1), the literal translation of the IE resulted in pragmatic failure.

Example (3)

$$
\text { دي ولا السفيرة عزيزة }
$$

She acts like Ms. Aziza

is originally one of the characters in a series of old Arabic tales called السيرة الهالالية but the expression is used now generally by Arabs to describe an arrogant woman. Translating it into "Ms. Aziza" clearly conveys wrong information because the TL audience would assume that the servant Amna, the one the speaker refers to in this scene, is called "Ms. Aziza"! The translation results in pragmatic failure because the TL audience cannot relate the English text to their prior knowledge.

Example (4)

هنفضل كده سداح مداح

Things will always be the same

This example is taken from the movie باب الحديد (Cairo Station). The expression سداح مداح is used in Egyptian Arabic to refer to a state of chaos and disorder. The students probably were unable to find an English 
equivalent that can create a similar effect, so they decided to resort to the strategy of deletion. This strategy clearly undermines the effect of the Arabic IE, and fails to produce a similar effect.

Example (5)

$$
\text { الجواز قسمة ونصيب }
$$

Marriages are made in heaven

This is one of the most commonly used expressions in Egyptian movies. The students here followed Baker's second suggested technique, namely, using a TL expression with a similar meaning but a different form. The translation, though has a distinct form, accurately expresses the intended message, and, thus, helps achieve pragmatic equivalence.

Example (6)

محش مالي عينه

He does not care about others

This example is also taken from the same movie باب الحديد. This expression is used to refer to a person who refuses to be bossed around by others. The students resorted to the technique of paraphrase that would have been effective if they actually had understood the intention of the speaker. A person who does not care about others is different from one who can be described as his own man. This example brings into attention the fact that failing to translate IEs is not necessarily related to lack of knowledge about the TL culture. In this example, the students, though they are all Arabs, were unable to figure out the meaning of the IE in the SL culture, and consequently, to render the intention of the speaker in the TL.

Example (7)

سييني دلوقتي لحسن دمي منغير

Leave me alone; I am in a black mood 


\section{Sama D. Salman}

(دمي متغير) is an Egyptian expression used when one is very much upset and not in the mood. It was translated with the English expression "black mood" that adequately expresses the meaning of the Arabic IE. The students chose an equivalent TL expression that is comprehensible by the TL audience and expresses the intention of the speaker. Pragmatic equivalence is achieved here through using a TL counterpart with a different form but with a similar meaning.

Example (8)

حسين مهز أة البلد من أولها لأخر ها؟

(Hussein) who is the village idiot?

The following seven examples are taken from the comedy movie إثاعة حب (A Rumor of Love).The expression مهزاة البلد من أولها لأخرها is used in Egyptian Arabic to refer to a naïve, stupid person. Realizing that literal translation would result in a meaningless expression, the students here tried to meet the assumptions of the TL audience by using a TL counterpart that carries the meaning of the SL IE though it has a different form. The strategy used helps achieve pragmatic equivalence.

Example (9)

$$
\text { ولنفرض أنها قبلت و اتجوزتلك، حتكرر حكايتي مع أم أربعه و أربعين }
$$

Let's say she married you, you'll be like me and my grumpy wife.

is a pejorative expression used in Egyptian Arabic to refer to an ill-tempered woman. The students resorted to the technique of paraphrase. The translation "grumpy wife" conveys the intention of the speaker and helps the TL audience draw the right inference. Pragmatic equivalence here is achieved though the students did not use a TL counterpart.

Example (10)

حتتجوز حسين ورجلك فوق رقبتك 
She will marry (Hussein) whether you like it or not

To express the meaning of forcing someone to do something unwillingly, Egyptians use the expression رجلك فوق رقبتك As it would sound funny and, of course, incomprehensible if it were translated literally, the students paraphrased this expression into "whether you like or not" which conveys the meaning of the Arabic SL IE though in a less powerful manner.

Example (11)

إنت متسو اش بصله

You look terrible

To describe a down-at-heel person, Egyptians use the expression انت . Paraphrasing helps rendering the sense of this IE but it does not produce a similar humorous effect on the TL audience. The students chose to sacrifice the humor in order to meet the expectations of the TL audience.

Example (12)

ده ميه من تحت تبن

He is such a womanizer

This proverb is used by Egyptians to describe a deceptive person. With a quick look at English proverbs, one can be misled into thinking that, "still waters run deep" could be a good choice, however, a deeper investigation reveals that the English proverb is used in a different context of situation. It, unlike the Arabic proverb, has positive connotations and is usually used to describe someone who does not talk much but has a passionate nature. Therefore, the students here preferred paraphrase to any other strategy. This example highlights the fact that translators, before calling a certain TL expression equivalent to the SL, should check the context in which the TL audience usually expect this expression to be used. 


\section{Sama D. Salman}

Example (13)

الكذب مالوش رجلين

We shouldn't have lied

This is a common Egyptian proverb that warns against the consequence of lying. It seems that the students here were unaware that there is an equivalent proverb in English that carries exactly the meaning of the Arabic proverb and is pragmatically equivalent to it, namely, "a lying tongue is only for a moment". Paraphrasing conveys the intention of the SL IE but fails to re-produce a similar effect.

Example (14)

راسي فيها مزيكة حسب الله

Oh my head is spinning

This example clearly shows how culture is reflected in the language of the society. مزيكة حسب اله is an Egyptian popular, loud type of music. This expression is used in Egyptian Arabic as a form of exaggeration to say that one is having severe headache. Since this type of music is culture bound, it cannot be translated literally. The TL audience in such a case will not be able to relate it to their knowledge of the world and, as a result, will not draw the right inference. The students, therefore, rendered its meaning by using an English counterpart that has a distinct form.

Example (15)

إنت ر افع راسنا

We are proud of you

This example is from the movie الر هينة (The Hostage). The expression رافع راسنا is used in Arabic to convey the sense of being proud of someone. When encountered with this IE, the students probably thought that literal translation would be incomprehensible by the TL audience so they preferred expressing the intention of the speaker by paraphrase. 
Example (16)

لو عايز تاكل عيش في البلد دي ماتكلمش كتير

If you want to live in peace, don't talk too much

Another example from the same movie is the IE تاكل عيش, which literally means, "to earn one's living", a sense that is clearly supported by the context of situation in which it is used. The students here translated it into "live in peace". This example emphasizes what has been said previously in example (6) that the students here were unable to figure out the meaning of the IE in the SL, and consequently, to render the intention of the speaker in the TL.

Example (17)

إنت عايز تعمل فيها سي السيد

You are not my master

This line is from تيمور وشفيقة (Taymour and Shafika). It is mentioned in a fight between a husband and a wife where the wife is accusing the husband of treating her as a slave that should listen to his orders. She describes him as سي السيد, the name of the main character in Naguib Mahfouz's trilogy, which has become a familiar way in Arabic to describe husbands who want to control their wives. Since the TL audience are unfamiliar with this character, and, hence, cannot draw the right inference, the students preferred paraphrasing the IE, as "you are not my master". The translation is pragmatically equivalent to the SL IE as it expresses the intention of the speaker, bringing into the mind the masterslave imagery.

Example (18)

لو ماكانتش كدبتلك انكثفت، كان زماني لسه نايم على وداني

If your lie did not come to light, I would have still been in the dark 


\section{Sama D. Salman}

The expression نايم على وداني is used in Egyptian Arabic to describe someone who is unaware of what is going on behind their back. The expression was translated into English using the counterpart "to be in the dark" which has the same meaning but a different form. The counterpart is pragmatically equivalent to the SL IE.

Example (19)

إنت في الإنجلش فلّة

Your English is really good!

This line is said in علة (molasses) movie (literally means a flower) is used in Egyptian Arabic to praise someone for the excellent performance. However, the expression is used here ironically because Masry, the name of the main character in the movie, is making fun of the English pronunciation of a little Egyptian girl. It seems that the students realized that literal translation will be meaningless, and they, therefore, resorted to paraphrase. In order to enable the TL audience to understand what is implied, the students paraphrased it into (good), hoping that the context of situation will guide the TL audience to make the inference.

Example (20)

دي فظيعة في الإنجليزي

She has a good grasp of English

This expression is also used in عسل أسود (molasses) movie. فظيعة (literally terrible) is meant here as a compliment. This IE is used in Egyptian Arabic to refer to something that is really good. Since its English literal meaning will not be accurate, as it is not used in English in such a context, the students paraphrased it into "good grasp of English".

Example (21)

ده زي القطة المغضة 
He is such a little angel

This example is taken from the movie صغيرة على الحب Too Young for Love". The expressional القطة المغمضة is used in Egyptian Arabic to describe an innocent person, though sometimes it could be used ironically as is the case with the context of this movie. Since the literal translation of this IE would probably sound weird for the TL audience, the students managed to achieve pragmatic equivalence through using a TL counterpart with a different form.

Example (22)

مش خايف لاياكلك البعبع ولا أبو رجل مسلوخة؟

Wasn't he worried you'd get eaten by bigfoot or the bogyman?

In the same movie, reference is made to البعبع و أبو رجل مسلوخة that are two mythical creatures used in the Egyptian culture to frighten children into good behavior. The students here were quite aware that literal translation would result in pragmatic failure, as the TL audience are not familiar with these names. Therefore, they used two different English lexical items that are usually used in the same context. The translation is pragmatically equivalent to the SL IE.

\section{Discussion}

The examples reveal that IEs should be dealt with skillfully when translating movies as mistranslation can lead to pragmatic failure, making the TL audience unable to grasp the intention of the speaker or draw the intended inference. The more the embedded cultural connotations of an idiomatic expression are, the more difficult it becomes to translate it into the other language. The examples also show that pragmatic equivalence for culture-specific IEs is achievable if the translator adopts the right translation strategy that fits the context. 


\section{Sama D. Salman}

The students used various strategies to deal with IEs. The most common strategy is paraphrase, adopted in (50\%) of the mentioned examples. Though this strategy sometimes cannot produce a similar effect on the TL audience (e.g. in case of humor), it can, as the examples show, re-express the intended meaning in a way that guides to the right inference.

Using a counterpart IE comes second with (31.8\%) of the examples. This seems to be the most effective way to deal with IE since it guarantees both re-expressing the intention of the speaker and producing a similar effect, thus achieving pragmatic equivalence. However, unlike other strategies, it requires highly competent translators who are very much familiar with the target culture to be able to use the right IE in the right context.

The next strategy is literal translation, which is adopted in $(13.6 \%)$ of the examples. Literal translation is not among the list of strategies suggested by Baker, probably because it, as the examples show, can lead to pragmatic failure. This is clearly shown in the first three examples mentioned, where it results in meaningless, incomprehensible renditions of the SL expressions.

Deletion is the least common strategy used by the subjects to render culture-specific terms, adopted in only (4.5\%) of the cases. Though omitting the IE seems the easiest choice, it is not preferred by the students. This is probably due to their keenness on faithfulness to the SL text. It can be said that this strategy should always be the last option and translators should not resort to it except when they are quite sure that there are textual and contextual clues that make the sense of the deleted IE easy to be grasped. 
Furthermore, the examples show that there is no one specific strategy to deal with IEs but the choice depends on two factors. The first one is the context of situation. Having a TL counterpart with similar meaning does not always mean that it should be used, as it may not fit the context in question (see example 12). The other factor is the pragmatic competence of the translator. It is this type of competence that enables the translator to find the most adequate TL counterpart that delivers the sense of the SL expression and produces a similar effect.

The analysis of the examples brings into surface the fact that pragmatic equivalence is relative and better be viewed as a continuum that ranges from optimum degree (using a TL counterpart with different form but similar meaning) to zero degree (literal translation). The type of strategy adopted determines how far pragmatic equivalence is achievable. As has been mentioned, there is no one preferred translation strategy but such decision is usually made on an ad hoc basis, depending on the context and the competence of the translator.

\section{Conclusion and Recommendations}

Since language and culture are closely interrelated, translation, in general, and subtitling, in particular, raises considerable cross-cultural issues. It can be said that where there is a cultural-specific expression, there is a translation problem due to distance between the SL culture and that of the TL. The greater the gap between the two cultures, the more challenging the task of the translators becomes. This, of course applies to English and Arabic that have different cultural backgrounds.

Movies usually contain many cultural components and expressions that in order to translate skillfully, translators should have sufficient linguistic and pragmatic awareness in the two languages in question. 


\section{Sama D. Salman}

The findings of the study support the hypothesis that pragmatic equivalence for culture-specific IEs is achievable, at varying degrees, depending on the type of translation strategy used by the translator. Using a TL counterpart that has a form distinct from that of the SL IE but similar meaning is shown to be the most effective strategy, while literal translation in most cases leads to pragmatic failure.

Students of subtitling should be trained to focus more on the intention and the context of the SL text. While translating, they should adopt a strategy that considers the pragmatic dimension, by looking for TL equivalents that carry similar communicative force to the SL idiomatic expressions and refraining from focusing on their literal meaning. This can never be achieved without having clear understanding of the whole context of situation in which these expressions are uttered. One way of doing so is by introducing classroom activities and challenging exercises that show how far culture-specific elements are reflected in language, and address the cultural differences between the two languages they are dealing with. Moreover, students should be advised to perfect their translation skills by acquiring pragmatic competence to be able to function in the culture of the language they are translating into as native speakers do.

Finally, although this study is only carried out on a small corpus of parts of only seven movies and the number of the participating students is limited, it is expected that the problems outlined and the strategies adopted would be similar with a larger corpus. 


\section{References}

Al Abwaini, S. (2013). Problems that translators face when they subtitle culturally-bound expressions from English into Arabic. (Master's thesis). Middle East University: Amman, Jordan. Retrieved from http://www.meu.edu.jo/ar/images/Problems that_Translators_Face

_When_They_Subtitle_Culturally-

Bound_Expressions_from_English_into_Arabic.pdf

Armellino, E. (2014). Translating culture-bound elements in subtitlingAn example of interlinguistic analysis: A scene from Scent of a Woman. Translation Journal. Retrieved from http://translationjournal.net/journal/44culturebound.htm

Ayoub, Y. (1994). Some linguistic and cultural problems in translating idiomatic expressions from Arabic into English and vice versa.(Unpublished master's thesis). Yarmouk University: Irbid, Jordan.

Baker, M. (1992). In other words: A coursebook on translation. London / New York: Routledge.

Cutting, J. (2002). Pragmatics and discourse: A resource book for students. London/New York: Routledge.

Durdureanu, I. (2011). Translation of cultural terms: Possible or impossible. JOLIE, 4, 51-63.

Fernando, C. \& Flavell, R. (1981). On idiom: Critical views and perspectives. Exeter: University of Exeter.

Georgakopoulou, P. (2009). Subtitling for the DVD industry. In Jorge Diaz Cintas and Gunilla Anderman (Eds.), Audiovisual translation: Language transfer on screen (pp. 21- 35). New York: Palgrave Macmillan. 


\section{Sama D. Salman}

Ghazala, H. (2002). Cross-cultural link in translation (English-Arabic). International Journal of Translation, 14(1), 138-162.

Grice, P. (1975). Logic and conversation. In P. Cole \& J. Morgan (Eds.), Syntax and semantics. 3: Speech acts (pp. 41-58). New York: Academic Press.

Hatim, B. \& Mason, I. (1990). Discourse and the translator. London: Routledge.

House, J. (1997). Translation quality assessment: A Model revisited. Tubingen: Gunter Narr Verlag.

Jakobson, R. (1959). On linguistic aspects of translation. In R.A. Brower (Ed.), On translation (pp. 232- 239). Retrieved from https://web.stanford.edu/ eckert/PDF/jakobson.pdf

Kenny, D. (2001). Equivalence. In M. Baker (Ed.), Routledge encyclopedia of translation studies (pp. 77-80). London/ New York: Routledge.

Koller, W. (1979). Equivalence in translation theory. In Andrew Chesterman (Ed.), Readings in Translation Theory (pp. 99-104). Finland: Oy Finn Lectura Ab.

Mahmoud, A. (2002). Interlingual transfer of idioms by Arab learners of English. The Internet TESL Journal, VIII (12). Retrieved from http://iteslj.org/Articles/Mahmoud-Idioms.html

Munday, J. (2001). Translation studies: Theories and applications. London/New York: Routledge.

Newmark, P. (1988). A textbook of translation. New York: Prentice Hall.

Nida, E (1964). Towards a science of translating: With special reference to principles and procedures involved in Bible translating. Leiden: E.J. Brill. 
Pedersen, J. (2005). How is culture rendered in subtitles? In MuTra $\begin{array}{llll}\text { Conference } & \text { Proceedings. } & \text { Retrieved } & \text { from }\end{array}$ http://www.euroconferences.info/proceedings/2005_Proceedings 12005_Pedersen_Jan.pdf

Pedersen, J. (2011). Subtitling norms for television. Amsterdam/Philadelphia: John Benjamins.

Perego, E. (2003). Evidence of explicitation in subtitling: Towards a categorization. Across Languages and Cultures 4 (1), 63-88.

Perez-Conzalez, L. (2014). Audiovisual Translation: Theories, Methods and Issues. New York: Routledge.

Ramière, N. (2006). Reaching a foreign audience: cultural transfers in audiovisual translation. Journal of Specialized Translation. 06. Retrieved from http://www.jostrans.org/issue06/art_ramiere.php

Sajna, M. (2013). Amateur subtitling - selected problems and solutions. Translation in Transition. 03 Retrieved from http://www.t21n.com/homepage/articles/T21N-2013-03-

Sajna.pdf

Salumahaleh, E. \& Mirzayi, K. (2014). Translation of culture-bound elements in Persian movies subtitled into English: A case study of the OSCAR winner 'A Segregation'. International Journal of English and Education. 3 (2), 221-236.

Skuggevik, E. (2009). Teaching screen translation: The role of pragmatics in subtitling. In Jorge Diaz Cintas and Gunilla Anderman (Eds.), Audiovisual translation: Language transfer on screen (pp. 197-213). New York: Palgrave Macmillan.

Suleiman, M. (2010). Difficulties that Jordanian graduate students majoring in the English language face when translating 


\section{Sama D. Salman}

culturally- bound expressions. (Unpublished Master's thesis). Middle East University: Amman, Jordan. 
